\title{
In situ XPS study of self-sustained oscillations in catalytic oxidation of propane over nickel
}

\author{
V.V. Kaichev ${ }^{\text {a }}$, A.Yu. Gladky ${ }^{\text {a }}$, I.P. Prosvirin ${ }^{\text {a }}$, A.A. Saraev ${ }^{\text {a }}$, M. Hävecker ${ }^{\text {, }}$, A. Knop-Gericke \\ ${ }^{\mathrm{b}}$, R. Schlögl ${ }^{\mathrm{b}}$ and V.I. Bukhtiyarov ${ }^{\mathrm{a}, *}$ \\ ${ }^{a}$ Boreskov Institute of Catalysis of the Siberian Branch of the Russian Academy of Science, \\ 5 Acad. Lavrentieva Pr., Novosibirsk 630090, Russia \\ ${ }^{b}$ Department of Inorganic Chemistry, Fritz Haber Institute of the Max Plank Society, \\ Faradayweg 4-6, D-14195 Berlin, Germany
}

\section{A B S T R A C T}

Self-sustained oscillations in the propane oxidation over a nickel foil were studied in situ with the use of ambient-pressure X-ray photoelectron spectroscopy (XPS) coupled with on-line mass-spectrometry and gas chromatography (GC). Regular oscillations of a relaxation type were observed at $0.5 \mathrm{mbar}$ in the temperature range of $600-750^{\circ} \mathrm{C}$ in oxygen-deficient conditions. $\mathrm{CO}$, $\mathrm{CO}_{2}, \mathrm{H}_{2}, \mathrm{H}_{2} \mathrm{O}$, and propylene were detected as products. $\mathrm{CO}$ selectivity in active half-periods achieved $98 \%$ decreasing to $40-60 \%$ in inactive half-periods. It has been found that the chemical state of the catalyst drastically changes together with the oscillations of the catalytic activity. According to the Ni2p and O1s core-level spectra measured in situ, the active catalyst surface is represented by metallic nickel, whereas it is covered with a layer of $\mathrm{NiO}$ with a thickness of at least $3 \mathrm{~nm}$ during the inactive half-periods. It means that the oscillations in the propane oxidation over nickel are originated from the reversible bulk oxidation of $\mathrm{Ni}$ to $\mathrm{NiO}$. We suggest that the propane oxidation over the metallic $\mathrm{Ni}$ surface occurs via the Langmuir-Hinshelwood mechanism, whereas the Mars-van Krevelen mechanism prevails when the reaction proceeds over NiO. The switching between the metallic surface and the oxide shows a significant change in the catalytic activity. According to GC measurements the activity of metallic nickel is approximately 40 -fold higher than that of $\mathrm{NiO}$.

\footnotetext{
${ }^{*}$ Corresponding author. Tel.: +7 (383) 3306771; fax: +7 (383) 3308356.

E-mail address: vib@catalysis.ru (V.I. Bukhtiyarov).
} 


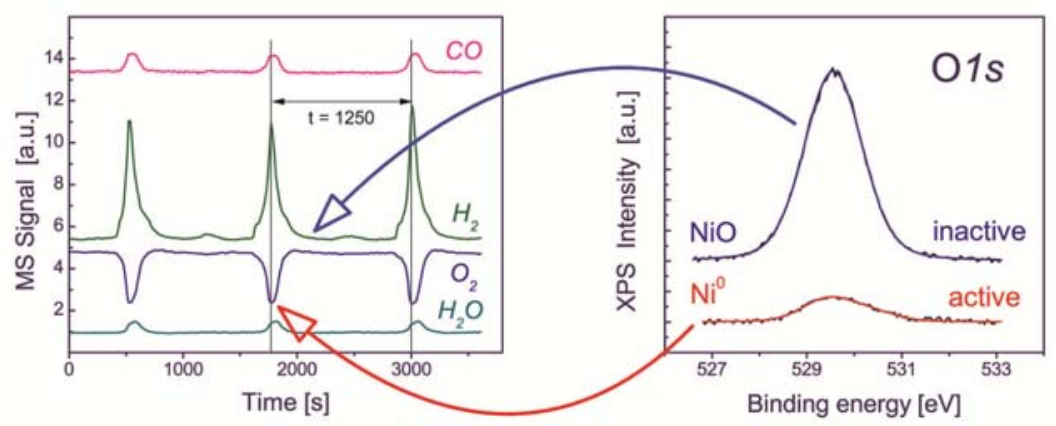

Keywords:

Heterogeneous catalysis

Propane oxidation

Nickel

Self-sustained oscillations

In situ ambient-pressure XPS 


\section{Introduction}

It is well-known that under certain conditions many heterogeneous catalytic reactions exhibit rate oscillations [1-5]. To date the self- sustained oscillations have been discovered in approximately 40 catalytic reactions in a wide range of pressures from ultrahigh vacuum (UHV) up to atmospheric pressure. It has been shown that this unusual phenomenon can appear as sinusoidal or harmonic oscillations, as relaxation-type oscillations, as well as chaos. It should be noted that the relaxation oscillations, in contrast to the harmonic ones, are characterized by two quite different time scales and can be described as fast evolution (jump up and jump down) between "low-active" and "high-active" states. The oscillations can be observed both in isothermal and in non-isothermal conditions. In some cases the kinetic oscillations are accompanied by a spatiotemporal self-organization in surface reactions that has been observed in detail by modern microscopic techniques $[6,7]$.

Many efforts have been spent in recent years to observe and to analyze the self-sustained oscillations in different catalytic reactions. However, overwhelming majority of the investigations was devoted to study the oscillation mechanism in the simplest catalytic systems such as the $\mathrm{CO}$ oxidation over Pt and Pd single-crystal surfaces in UHV. The experimental results of these studies have stimulated appearance of numerous theoretical models which not only explained the origin of the kinetic instabilities, but also tried to predict the oscillatory behavior under certain conditions [3]. However, these models cannot be directly applied for more complicated reactions, such, for instance, as oxidation of light alkanes over VIII group metals.

The self-sustained oscillations of the methane oxidation rate have been observed over a great variety of catalysts including $\mathrm{Ni}$ wires, foils, and foams, $\mathrm{Ni} / \mathrm{Cr}$ alloys, Co foils, $\mathrm{Pd}$ films and foils, as well as $\mathrm{Ni}, \mathrm{Pd}, \mathrm{Rh}$, and $\mathrm{Ru}$ supported particles [8-24]. Recently, the rate oscillations of the ethane oxidation over $\mathrm{Ni}, \mathrm{Co}$, and $\mathrm{Pd}$ foils have been also reported $[25,26]$. Our previous works have shown that the regular oscillations with a period of several minutes can be also realized for the partial oxidation of propane to synthesis gas over nickel at pres- sures of approximately 1 mbar [27,28]. For all aforementioned hydro- carbons the relaxation oscillations of concentrations of both reactants and products as well as the oscillations of the catalyst temperature have been observed. Other general peculiarity for the reactions was the fact that the stable repeatable oscillations in the oxidation of light alkanes appeared after an induction period which was characterized by a low catalytic activity and varied from several minutes to a few 
hours. During the induction period a rough, highly-porous structure of the subsurface catalyst layers was produced on the catalyst surface $[11,27]$. Therefore, the rate oscillations are likely to be associated with slow reversible transformation of the catalyst surface. Similarity in oscillation patterns in all mentioned catalytic systems allowed us to suggest their common origin.

Numerous mechanisms describing the rate oscillations for different heterogeneous catalytic reactions were proposed over the last 30 years [1-5]. However, only three hypotheses can explain the rate oscillations of the oxidation of light alkanes over transition metal catalysts, namely a reconstruction model [29], a carbon model [30], and an oxide model [31]. The first model was drawn from the results of the ultrahigh-vacuum study of the $\mathrm{CO}$ oxidation over $\mathrm{Pt}$ single-crystal surfaces. The rates of $\mathrm{CO}$ and oxygen adsorption vary due to the surface reconstruction and depend on the adsorption layer composition. Another typical example of the reconstruction case is the partial oxidation of methanol to formaldehyde over silver catalysts. In this reaction surface reconstruction strongly affects the oxygen adsorption characteristics, which in turn influence the catalyst performance [32]. Strong reaction-induced changes of the catalyst morphology were also observed under ambient pressure in other catalytic systems [33-35]. The other two models link the rate oscillations to a periodic deactivation of the catalyst surface either due to the accumulation of carbonaceous deposits or due to the formation of a surface oxide layer.

This study was performed to discriminate between these three models and to obtain information about the chemical state of the catalyst surface under the oxidation of light alkanes in the self-oscillation regime. To achieve this goal, ambient-pressure X-ray photoelectron spectroscopy, which is one of the most useful tools to investigate the surface composition and the nature of adsorbed species [36,37], was chosen. Its combination with mass-spectrometry (MS), which can monitor the gas-phase composition, becomes a particularly effective in situ technique, making it possible to correlate the surface composition with the catalyst performance.

Since the catalytic oxidation of propane over nickel exhibits oscillatory behavior in the millibar pressure range, that is the upper limit for in situ measurements with XPS, namely this reaction was chosen for the case investigation. In the current study we used the combined ambient-pressure XPS-MS approach to detect the chemical state of the surface of the nickel foil during the active and inactive half-periods of oscillations in the propane oxidation. In some experiments the product composition was also analyzed by on-line gas-chromatography. 


\section{Experimental details}

The experiments were performed at the ISISS beamline at the Berlin electron storage ring for synchrotron radiation (BESSY II). The experimental setup was described in detail elsewhere [37]. A key feature of this setup, which makes it possible to acquire photoelectron spectra under millibar pressure, is the differential pumping between a high-pressure cell and an electron energy analyzer (PHOIBOS-150, SPECS). The high-brilliance synchrotron radiation along with a short travel path of the photoelectrons through the high-pressure zone allows us to obtain the highquality photoelectron spectra at pressures up to 2 mbar. All spectra were normalized to the incident photon flux and to the ring current. The photoelectron take-off angle (measured from the sample surface) was $90^{\circ}$. The binding energy was referenced to the Fermi edge in the valenceband spectra of a metallic nickel for each experiment. The Ni2 $p_{3 / 2}, \mathrm{O} 1 \mathrm{~s}$, and $\mathrm{C} 1 \mathrm{~s}$ spectra were usually obtained using the photon energies of 1050,730 , and $485 \mathrm{eV}$, respectively, that provides the same kinetic energy (approximately $200 \mathrm{eV}$ ) for each region. This is important to assure the same information depth for all elements. In depth profiling experiments, the kinetic energy of the $\mathrm{Ni} 2 p$ photoelectrons varied from $200 \mathrm{eV}$ to approximately $500 \mathrm{eV}$, when the photon energy was $1350 \mathrm{eV}$. The spectra were curve-fitted after a Shirley-type background subtraction. The lineshape was assumed to be a mixture of Gaussian and Lorentzian functions. To fit the Ni2p $3 / 2$ spectrum from the active surface, an analytical Doniach-Sanjic function convolved with Gaussian was used [38].

The propane and oxygen flows were regulated separately with calibrated mass-flow controllers. In all experiments, the oxygen flow was $0.65 \mathrm{sccm}$, while the propane flow was varied in the range of 1.9-9.3 $\mathrm{sccm}$ depending on the required propane/oxygen ratio. The total pressure of reaction mixtures in the high-pressure cell was kept at a constant level of 0.5 mbar. The gas-phase composition was monitored continuously with an on-line quadrupole massspectrometer (Prizma QMS-200, Pfeiffer) connected through a leak valve to the high-pressure cell. A rectangular piece of a nickel foil $(0.125 \times 6 \times 7 \mathrm{~mm}$, purity $99.99 \%$, Advent $)$ was used as a catalyst. The foil was mounted onto a sapphire sample holder with a $\mathrm{SiC}$ plate heated from the rear with a NIR semiconductor laser $(\lambda=808 \mathrm{~nm})$ [39]. The undoubted advantage of this heating system is the absence of any hot spots, which might have high catalytic activity. The sample temperature was monitored with a chromel-alumel thermocouple spot-welded directly to the foil edge. The GC analysis was made only in the experiment with the propane/oxygen ratio of 9:1 at 
$680^{\circ} \mathrm{C}$ using an on-line four-channel micro gas chromatograph (CP-4900, Varian) equipped with thermal conductivity detectors.

\section{Results and discussion}

Before in situ experiments, a nickel foil catalyst was activated at $750^{\circ} \mathrm{C}$ in the reaction mixture $\left(\mathrm{C}_{3} \mathrm{H}_{8}: \mathrm{O}_{2}=9: 1\right.$, total pressure of 1 mbar, mixture flow of $\left.60 \mathrm{sccm}\right)$ for $1.5 \mathrm{~h}$ in a flow reactor described elsewhere [28]. In full agreement with our previous results [27], the catalyst pretreated in these conditions exhibits the self-sustained oscillations immediately after the heating in the reaction mixture without an induction period. In the present study, the oscillations were observed at $600-700^{\circ} \mathrm{C}$ for the propane/oxygen molar ratios from $3: 1$ to $15: 1$ at 0.5 mbar.

Fig. 1 shows a typical pattern of the reaction rate oscillations. The catalyst was in an inactive state for the most of the time with periodical evolutions of the reaction products: $\mathrm{H}_{2}$, $\mathrm{CO}$, and $\mathrm{H}_{2} \mathrm{O}$. Mass-spectrometric detection of $\mathrm{CO}_{2}$, which is one of the possible reaction products, is complicated due to overlapping of the $\mathrm{CO}_{2}$ cracking signals at $\mathrm{m} / \mathrm{z}=12,16,28$, and 44 with the propane cracking pattern. Therefore, the $\mathrm{CO}_{2}$ yield was not controlled by massspectrometry in this study. However, in our previous experiments with isotope-labeled oxygen

${ }^{18} \mathrm{O}_{2}$, the $\mathrm{CO}_{2}$ yield was observed to be synchronized with $\mathrm{H}_{2} \mathrm{O}$ [27]. The MS signals at $\mathrm{m} / \mathrm{z}=2$ $\left(\mathrm{H}_{2}\right), \mathrm{m} / \mathrm{z}=18\left(\mathrm{H}_{2} \mathrm{O}\right), \mathrm{m} / \mathrm{z}=28(\mathrm{CO})$, and $\mathrm{m} / \mathrm{z}=32\left(\mathrm{O}_{2}\right)$ oscillate with the period of $1250 \mathrm{~s}$.

$\mathrm{CO}$ and $\mathrm{H}_{2} \mathrm{O}$ peaks exhibit a similar shape with the characteristic width of approximately $140 \mathrm{~s}$ : their evolutions with time are followed by a slow descent to the initial level of the low catalytic activity (Fig. 1). The oscillatory peaks of $\mathrm{H}_{2}$ have a slightly different shape: the $\mathrm{H}_{2}$ signal shows a pronounced shoulder, which is followed by a sharp peak with a long tail. Such shape of the $\mathrm{H}_{2}$ signal indicates that hydrogen might evolve at different stages of the oscillations: during the transition from the inactive state to the active state, during the active state, and during the reverse transition from the active state to the inactive state. Oxygen oscillations have the inverse form: $\mathrm{O}_{2}$ uptake is observed in the active half-periods. All these data indicate the existence of at least two states of the catalyst surface with the different activities in the propane oxidation.

Fig. 1 shows also that the periodic changes of the product/reactant concentrations are accompanied with the variation of the catalyst temperature. It should be stressed that the sample was heated with a NIR laser working at the fixed power. Therefore, these temperature 
oscillations with the peak-to-peak amplitude of more than $20^{\circ} \mathrm{C}$ cannot be the result of heating artifacts and reflects the chemical reactions occurring on the catalyst surface.

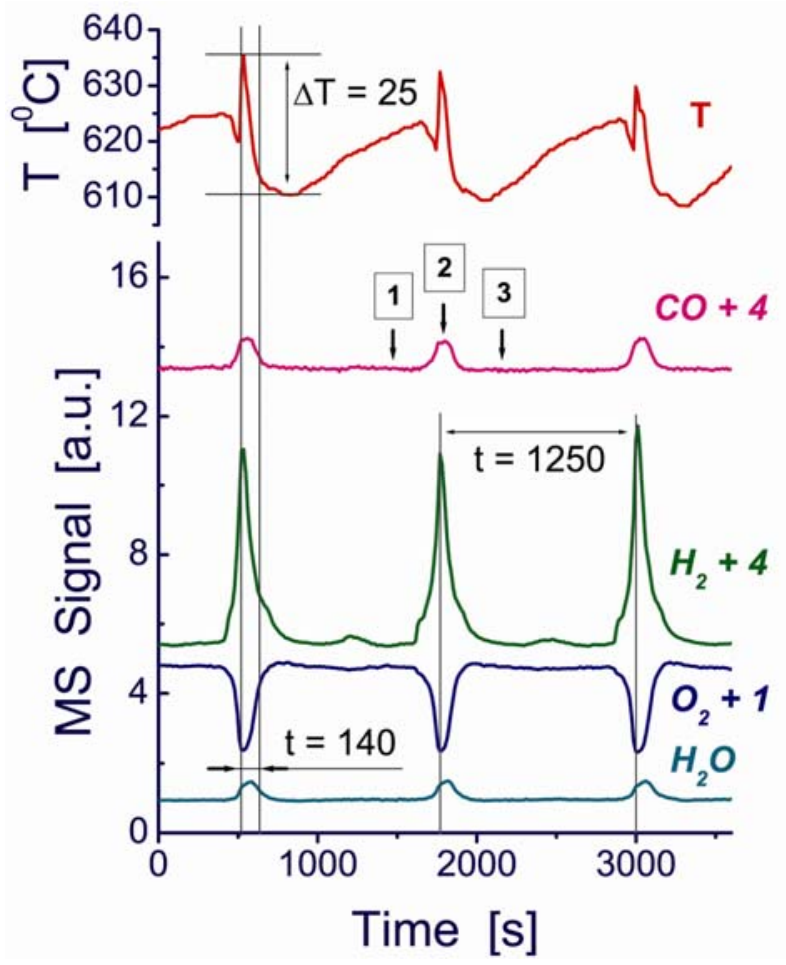

Fig. 1. Self-sustained oscillations in the propane oxidation over the Ni foil at 0.5 mbar with the propane/oxygen ratio of 8:1. The MS signals from $\mathrm{H}_{2}, \mathrm{CO}$, and $\mathrm{O}_{2}$ are vertically shifted by the factor shown in the legends.

According to the on-line GC measurements, the propane conversion oscillates in the range from 0.5 to $23 \%$. Such products as $\mathrm{H}_{2}, \mathrm{CO}, \mathrm{CO}_{2}$, and propylene were detected by GC. $\mathrm{CO}$ selectivity during the active half-periods achieved 98\%, while the selectivity towards byproducts such as $\mathrm{CO}_{2}$ and $\mathrm{C}_{3} \mathrm{H}_{6}$ was only $1-2 \%$. It means that the main route during the active half-periods is the partial oxidation of propane to synthesis gas. During the inactive half-periods, CO selectivity is in the range of $40-60 \%$.

The oscillations of the catalyst temperature show a more complex waveform (Fig. 1). The temperature decrease coincides with the beginning of the oxygen uptake, while the sharp increase of temperature is accompanied with the formation of all products. A maximum temperature corresponds to the highest rate of $\mathrm{H}_{2}$ evolution. After the maximum, the temperature decays to a minimum, which coincides with almost full termination of all catalytic reactions. The 
gradual temperature rise during the inactive half-period is observed until the next temperature peak. Such complicated behavior of the catalyst temperature and the complex shape of $\mathrm{H}_{2}$ peaks point that a few chemical processes occur simultaneously over the catalyst surface during the oscillations.

$\mathrm{O}_{2}$ conversion during the active half-period was not the same for different experiments, varying in the wide range from 15 to $84 \%$, that, however, did not affect the oscillation period. This observation allows us to conclude that the appearance of self-sustained oscillations is not due to the heat and mass transport limitations as it occurs usually in continuous stirred tank reactors for the reactions with strongly non-linear kinetics [2]. It is more probably that the oscillations originate from the change of the chemical state of the catalyst surface. In order to characterize the catalyst surface in the active and inactive states, XPS spectra were taken in situ during the oscillations. The long period and the regular character of oscillations made it possible to acquire several scans of the $\mathrm{Ni} 2 p_{3 / 2}$ and $\mathrm{O} 1 s$ core-level spectra during the active and inactive half-periods, and then to average these scans to improve the signal-to-noise ratio. The $\mathrm{C} 1 \mathrm{~s}$ spectra were also acquired; however, the strong signal from gas-phase propane at 285-286 eV completely masks the signal of the carbon-containing adsorbates like $\mathrm{C}_{\mathrm{x}} \mathrm{H}_{\mathrm{y}} \mathrm{O}_{\mathrm{z}}$ (spectra not shown here). Nevertheless, the C1s spectra unambiguously show that neither nickel carbide nor dissolved carbon features at $282-283 \mathrm{eV}$ are observed both in the active state and in the inactive state.

Fig. 2 shows the Ni2 $p_{3 / 2}$ and O1s core-level spectra taken when the system has passed through three characteristic points, which correspond to the inactive and active states. These points are marked as 1, 2, and 3 in Fig. 1. One can see that the binding energy (BE) and the shape of the Ni2 $p_{3 / 2}$ spectra are completely changed when the catalyst surface passes from the inactive to the active state. The spectra from the inactive surface consist of the main component at $854.6 \mathrm{eV}$ with a pronounced high $\mathrm{BE}$ shoulder and an additional wide component at $861 \mathrm{eV}$. The latter feature is a shake-up satellite originating from the multi-electron transitions during the XPS process [40-42]. Typically, the intense shake-up satellites are observed in the spectra of paramagnetic $\mathrm{Ni}(\mathrm{II})$ compounds such as $\mathrm{NiO}, \mathrm{Ni}(\mathrm{OH})_{2}, \mathrm{NiAl}_{2} \mathrm{O}_{4}$, etc, whereas the spectra of metallic nickel and diamagnetic $\mathrm{Ni}$ (III) compounds do not show shake-up satellite peaks [40-43]. On the other hand, the pronounced high $\mathrm{BE}$ shoulder, which is $1.8 \mathrm{eV}$ above the main $\mathrm{Ni} 2 p_{3 / 2}$ peak, is the unique feature of $\mathrm{NiO}$ and is not observed in the $\mathrm{Ni} 2 p_{3 / 2}$ spectra of nickel hydroxide and nickel aluminate. Moreover, the intensity of this shoulder is highly sensitive to the long- 
range structure, and therefore this feature is characteristic of bulk NiO. For instance, it was observed in the spectra of thick $\mathrm{NiO}$ films, but not in the spectra of monolayer NiO films [40]. Hence, the Ni2 $p_{3 / 2}$ spectra undoubtedly indicate that during the inactive half-period, the $\mathrm{Ni}$ foil surface is covered by a thick film of $\mathrm{NiO}$. It should be stressed that the $\mathrm{Ni} 2 p$ spectra exhibit no nickel carbide and metallic nickel features near $853 \mathrm{eV}$.
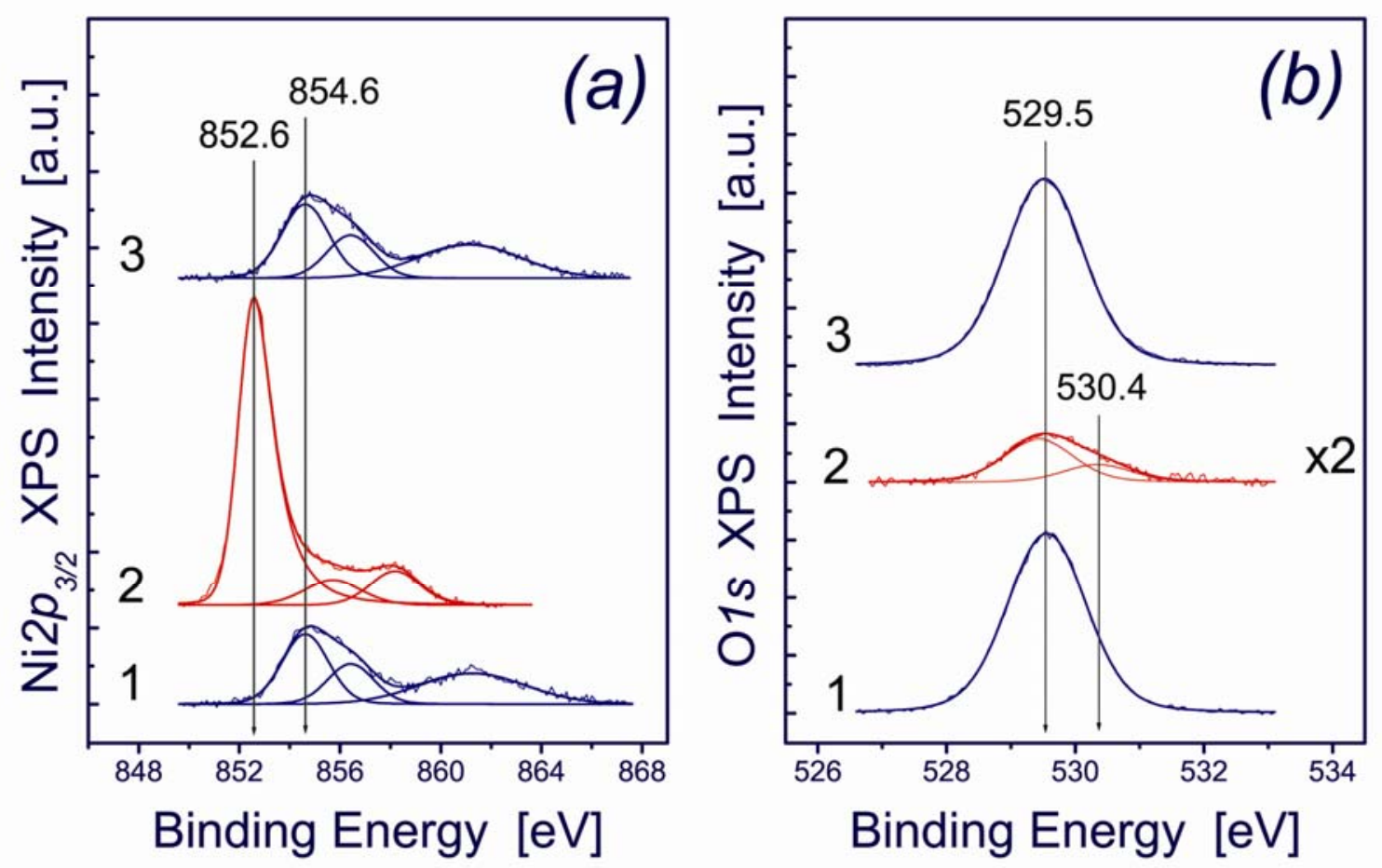

Fig. 2. Ni2p $p_{3 / 2}$ (a) and O1s (b) core-level spectra obtained during the inactive and active halfperiods of the oscillations. Spectra 1 and 3 correspond to the inactive state; spectrum 2 corresponds to the active state (see markers in Fig. 1).

In contrast, a narrow component at $852.6 \mathrm{eV}$, which is the main peak in the $\mathrm{Ni} 2 p_{3 / 2}$ spectrum from the active surface (Fig. 2a, spectrum 2), is typical of metallic nickel. Two weaker components at 855.7 and $858.2 \mathrm{eV}$ can be associated with energy loss peaks due to Plasmon excitations in metal [42]. It should be noted that some authors suppose that the last, so-called 6 $\mathrm{eV}$ satellite, is due to a final-state shake-up process or an initial-state configuration-mixing effect, both the effects being characteristics of metallic Ni $[44,45]$. Therefore, the transition from the inactive to the active state corresponds to the full reduction of the catalyst surface. Formation of nickel carbide in this case is excluded by the absence of the feature at $282 \mathrm{eV}$ in the $\mathrm{C} 1 \mathrm{~s}$ spectra. 
In good agreement with the transformation of the $\mathrm{Ni} 2 p_{3 / 2}$ spectra, the corresponding changes were observed in the O1s spectra as shown in Fig. 2b. The O1s spectra of the inactive surface (Fig. 2b, spectrum 1) consist of a single narrow component at $529.5 \mathrm{eV}$, which can be unambiguously assigned to oxygen in the $\mathrm{NiO}$ lattice. This conclusion is based on closeness of the O1s binding energy to literature data for bulk NiO: $529.5-530.2 \mathrm{eV}[41,46,47]$, and of the $\mathrm{O} / \mathrm{Ni}$ atomic ratio (1.2) to stoichiometric value for the oxide. The absence of higher $\mathrm{BE}$ components in the $\mathrm{O} 1 \mathrm{~s}$ spectrum indicates that the concentration of hydroxyl groups $\left(\mathrm{Ni}(\mathrm{OH})_{2}\right.$ is characterized by the $\mathrm{O} 1 \mathrm{~s}$ feature at $531.2-531.6 \mathrm{eV}[41,46,47])$ in our $\mathrm{NiO}$ film is below the XPS detection limit.

The transition to the active state leads to a profound decrease in the O1s intensity (Fig. $2 \mathrm{~b}$, spectrum 2). In this case the spectrum can be fitted to two components at 529.4 and 530.4 $\mathrm{eV}$. It should be noted that the O1s binding energies for chemisorbed oxygen and for lattice oxygen of $\mathrm{NiO}$ are almost the same with the difference less than $0.3 \mathrm{eV}$ [47]. Therefore, taking into account that the $\mathrm{Ni} 2 p_{3 / 2}$ spectrum is typical of metallic nickel, the first component at 529.4 $\mathrm{eV}$ should be assigned to the chemisorbed oxygen species, while the second component at 530.4 $\mathrm{eV}$ could be due to subsurface or dissolved oxygen species. After subsequent transition to the inactive state, the $\mathrm{O} 1 \mathrm{~s}$ peak at $529.5 \mathrm{eV}$ restores its intensity. According to our rough estimation, the oxygen coverage during the active half-periods is in the range between 0.2 and 0.4 monolayer.

Thus, in situ XPS spectra clearly indicate that during the inactive half-periods, the Ni foil is covered with the $\mathrm{NiO}$ layer. However, the presence of small amounts of other oxidic species, such as $\mathrm{Ni}(\mathrm{OH})_{2}$ or $\mathrm{Ni}_{2} \mathrm{O}_{3}$, cannot be ruled out. The transition to the active state corresponds to the full reduction of $\mathrm{NiO}$ to metallic nickel. It means that during the oscillations, the periodic reduction and oxidation occur within upper layers of the nickel foil. It should be underlined that no $\mathrm{Ni}^{0}$ features in the $\mathrm{Ni} 2 p$ spectra of the inactive surface were observed even for the photon energy of $1350 \mathrm{eV}$, when the kinetic energy of the $\mathrm{Ni} 2 p$ photoelectrons was approximately 500 $\mathrm{eV}$. Taking into account that the inelastic mean free path of electrons $(\lambda)$ with the kinetic energy of $500 \mathrm{eV}$ in $\mathrm{NiO}$ is $10.6 \AA[48,49]$ and the XPS information depth is $3 \lambda$, the thickness of the $\mathrm{NiO}$ layer should exceed $32 \AA$. Thus, the oscillations originate from the changes of oxidation state of the catalyst bulk.

This conclusion is supported not only by the XPS data, but also by the analysis of the temperature profile (Fig. 1). Indeed, the temperature drop, which occurs simultaneously with the 
oxygen uptake, indicates that at least one reaction in the system is endothermic. The main reactions, i.e., the partial oxidation of propane to the synthesis gas:

$$
\mathrm{C}_{3} \mathrm{H}_{8}+1.5 \mathrm{O}_{2} \rightarrow 3 \mathrm{CO}+4 \mathrm{H}_{2} \quad \Delta H_{298}^{0}=-228 \mathrm{~kJ} / \mathrm{mol}
$$

the total oxidation of propane to $\mathrm{CO}_{2}$ and water:

$$
\mathrm{C}_{3} \mathrm{H}_{8}+5 \mathrm{O}_{2} \rightarrow 3 \mathrm{CO}_{2}+4 \mathrm{H}_{2} \mathrm{O} \quad \Delta \mathrm{H}_{298}^{0}=-2044 \mathrm{~kJ} / \mathrm{mol}
$$

and water-gas-shift reaction:

$$
\mathrm{CO}+\mathrm{H}_{2} \mathrm{O} \rightarrow \mathrm{CO}_{2}+\mathrm{H}_{2} \quad \Delta H_{298}^{0}=-41 \mathrm{~kJ} / \mathrm{mol}
$$

which should be also taken into account despite low $\mathrm{CO}_{2}$ yield, are exothermic [50] and cannot explain the temperature drop. Alternative reactions producing $\mathrm{CO}$ and $\mathrm{H}_{2}$ are steam and $\mathrm{CO}_{2}$ reforming of propane:

$$
\begin{array}{ll}
\mathrm{C}_{3} \mathrm{H}_{8}+3 \mathrm{H}_{2} \mathrm{O} \rightarrow 3 \mathrm{CO}+7 \mathrm{H}_{2} & \Delta H_{298}^{0}=+498 \mathrm{~kJ} / \mathrm{mol} \\
\mathrm{C}_{3} \mathrm{H}_{8}+3 \mathrm{CO}_{2} \rightarrow 6 \mathrm{CO}+4 \mathrm{H}_{2} & \Delta H_{298}^{0}=+621 \mathrm{~kJ} / \mathrm{mol}
\end{array}
$$

Although both these reactions are endothermic, they still cannot explain the temperature drop. Indeed, being secondary reactions, they are based on the highly exothermic production of $\mathrm{CO}_{2}$ and $\mathrm{H}_{2} \mathrm{O}$. Moreover, since steam and $\mathrm{CO}_{2}$ reforming is relatively slow reactions compared to the oxidation reactions (Eqs. (1) and (2)), they cannot strongly affect the catalyst temperature [50]. The most possible reason, explaining the temperature drop, is the stoichiometric reduction of the nickel oxide with propane:

$$
3 \mathrm{NiO}+\mathrm{C}_{3} \mathrm{H}_{8} \rightarrow 3 \mathrm{Ni}+3 \mathrm{CO}+4 \mathrm{H}_{2} \quad \Delta \mathrm{H}_{298}^{0}=+491 \mathrm{~kJ} / \mathrm{mol}
$$

However, in order to provide the observed lowering the catalyst temperature by $25^{\circ} \mathrm{C}$ (Fig. 1), a reasonably thick oxide layer should react with propane. Subsequent slow increasing the catalyst temperature during the inactive half-periods can be due to the exothermic oxidation:

$$
\mathrm{Ni}+0.5 \mathrm{O}_{2} \rightarrow \mathrm{NiO} \quad \Delta \mathrm{H}_{298}^{0}=-240 \mathrm{~kJ} / \mathrm{mol}
$$

of deeper and deeper nickel layers.

Summarizing the presented data, we can conclude that in spite of strong restructuring of the nickel surface during the induction period [27], the oscillation mechanism of the propane oxidation over $\mathrm{Ni}$ cannot be explained in terms of the reconstruction model, but originates from 
the periodic oxidation and reduction of the surface and subsurface layers of the catalyst. The absence of the $\mathrm{C} 1 \mathrm{~s}$ features from nickel carbide or from dissolved carbon allows us also to exclude the carbon model.

To the best of our knowledge, this work is the first direct experimental evidence of the redox mechanism of the self-sustained oscillation in the oxidation of light alkanes over transition metals. The oxide model was earlier proposed by Sales, Turner and Maple (STM) for the oscillations in the CO oxidation over Pt, Pd, and Ir [31]. The main feature of the STM model is the formation of surface oxide species which block the surface adsorption sites. The slow oxidation followed by the reduction of the metal surface layer induces transitions between two branches of the Langmuir-Hinshelwood reaction mechanism inducing the oscillations [31]. In contrast with the STM model, the oscillations in the propane oxidation over nickel are controlled by the reversible bulk oxidation of $\mathrm{Ni}$ to $\mathrm{NiO}$. According to $\mathrm{GC}$ measurements, the switching between the metallic surface and the oxide shows a significant decrease in catalytic activity. This, together with the variation in the product distribution observed for the active and inactive half-periods, suggests the changes in the reaction mechanisms. We guess that the LangmuirHinshelwood mechanism is realized for the propane oxidation over the metallic Ni surface, whereas the reaction over $\mathrm{NiO}$ follows the Mars-van Krevelen mechanism where the oxidation of propane with the $\mathrm{NiO}$ lattice oxygen is coupled with subsequent reoxidation of the reduced surface by oxygen from the gas phase [51]. Considering the propane oxidation as a case reaction, we suppose that the rate oscillations in the oxidation of other light alkanes over transition metals (like $\mathrm{Ni}, \mathrm{Co}$, etc) proceed through the similar mechanism.

A similar mechanism was recently proposed by Hendriksen and coworkers [52,53] for the oscillations in the rate of $\mathrm{CO}$ oxidation over $\mathrm{Pt}$ and $\mathrm{Pd}$ observed under atmospheric conditions. The authors supposed that the high-pressure reaction oscillations were not due to the bistability in the Langmuir-Hinshelwood kinetics, but arose from the periodic switching between the low-reactive metallic surface and the high-reactive oxide surface. The reaction over metallic surface follows the Langmuir-Hinshelwood mechanism, whereas metal-to-oxide transition changes the reaction to the Mars-van Krevelen mechanism. It seems that the STM mechanism, as well as the so-called subsurface oxygen mechanism [54] based on an assumption that the oscillation in catalytic activity is caused by the variation of oxygen sticking probability under the influence of subsurface oxygen, is realized at vacuum conditions only. At elevated pressures the 
self-sustained oscillations in catalytic oxidation reactions over transition metals are more probably to follow the redox mechanism based on the reversible bulk oxidation of the catalyst.

The reasons causing the transition between the active and inactive states or between metallic $\mathrm{Ni}$ and $\mathrm{NiO}$ are not clear yet. One of the possible reasons was discussed in the cited paper by Hendriksen et al. [53], who proposed that formation and annealing of the surface atomic steps is a driving force for reduction-oxidation during oscillations of $\mathrm{CO}$ oxidation over Pt under elevated pressures. Using in situ XRD, they identified the processes of smoothening of the metal surface and roughening of the oxide one during inactive and active half-periods of the oscillation, respectively.

One can also suppose that dissolved or subsurface oxygen in metallic nickel and/or defects in NiO play an important role for feedback mechanism. For instance, interconnection between the number of oxygen vacancies and catalytic activity in the $\mathrm{CO}$ oxidation was recently reported for the $\mathrm{RuO}_{2}$ catalysts [55]. It has been shown that completely oxidized polycrystalline ruthenium dioxide $\left(\mathrm{RuO}_{2}\right.$ pre-calcined in $\mathrm{O}_{2}$ at $\left.1073 \mathrm{~K}\right)$ does not exhibit any activity and a long induction period in the feed at $503 \mathrm{~K}$ is necessary to activate $\mathrm{RuO}_{2}$, which then provides $100 \%$ conversion of $\mathrm{CO}$. At the same time, in situ XRD reveals no changes in the $\mathrm{RuO}_{2}$ diffraction pattern before and after the induction period. High activity was explained by the formation of the defects in ruthenium oxide [55].

By analogy with this example, we can speculate that the transition between the active and inactive states proceeds through some transient states, which are similar to a solid solution of oxygen in metallic nickel or to highly defective nickel oxide. Appearance of the defects in $\mathrm{NiO}$ can facilitate the heterolytic activation of $\mathrm{C}-\mathrm{H}$ bond of propane (the key step in the Mars-van Krevelen mechanism) increasing the rate of propane interaction with lattice oxygen. Fast removal of oxygen will reduce $\mathrm{NiO}$ to $\mathrm{Ni}$. The solid solution of oxygen in metallic nickel above a critical level can lead to the back transformation of the surface layers to nickel oxide.

\section{Summary}

The self-sustained oscillations in the propane oxidation over a nickel foil have been studied in situ with the use of ambient-pressure XPS coupled with on-line mass-spectrometry and gas chromatography. According to the $\mathrm{Ni} 2 p$ and $\mathrm{O} 1 s$ core-level spectra of the catalyst surface, during the active half-period nickel in the surface and subsurface layers is in the metallic state, whereas during the inactive half-periods the catalysis surface is covered with a layer of 
$\mathrm{NiO}$ with a thickness of at least $3 \mathrm{~nm}$. GC measurements showed that the activity of metallic nickel is approximately 40 -fold higher than that of $\mathrm{NiO}$. We suggest that propane oxidation over the metallic Ni surface occurs according to the Langmuir-Hinshelwood mechanism and the main reaction route is the partial propane oxidation to $\mathrm{CO}$ and $\mathrm{H}_{2}$, whereas the reaction over $\mathrm{NiO}$ follows the Mars-van Krevelen mechanism, not only $\mathrm{CO}$, but also $\mathrm{CO}_{2}$ and propylene being detected among the products of propane oxidation in this case. Hence, the reversible reduction/oxidation of the catalyst bulk affects strongly the catalytic properties of nickel and even changes the mechanism of propane oxidation.

\section{ACKNOWLEDGMENT}

The authors gratefully acknowledge Dr. D. Teschner, Dr. R. Blume, Dr. A. Oestereich from Fritz Haber Institute and the BESSY staff for their continuous support during the beamtime. The work was partially supported by RFBR (research project No. 11-03-00498-a) and by the Siberian Branch of the Russian Academy of Science (project No. 81).

\section{REFERENCES}

[1] G. Ertl, Adv. Catal. 37 (1990) 213-277.

[2] F. Schüth, B.E. Henry, L.D. Schmidt, Adv. Catal. 39 (1993) 51-127.

[3] R. Imbihl, Prog. Surf. Sci. 44 (1993) 185-343.

[4] M.M. Slinko, N.I. Jaeger, Stud. Surf. Sci. Catal. 86 (1994) 1-387.

[5] R. Imbihl, G. Ertl, Chem. Rev. 95 (1995) 697-733.

[6] V. Gorodetskii, J. Lauterbach, H.-H. Rotermund, J.H. Block, G. Ertl, Nature 370 (1994) 276-279.

[7] M. Kim, M. Bertram, M. Pollmann, A. von Oertzen, A.S. Mikhailov, H.H. Rotermund, G. Ertl, Science 292 (2001) 1357-1360.

[8] D. König, W.H. Weber, B.D. Poindexter, J.R. McBride, G.W. Graham, K. Otto, Catal. Lett. 29 (1994) 329-338.

[9] Y. Deng, T.G. Nevell, Faraday Discuss. 105 (1996) 33-46.

[10] Y. Deng, T.G. Nevell, J. Mol. Catal. A 142 (1999) 51-60.

[11] G.W. Graham, D. König, B.D. Poindexter, J.T. Remillard, W.H. Weber, Top. Catal. 8 (1999) 35-43.

[12] X. Zhang, D.M.P. Mingos, D.O. Hayward, Catal. Lett. 72 (2001) 147-152. 
[13] X. Zhang, D.O. Hayward, D.M.P. Mingos, Catal. Lett. 83 (2002) 149-155.

[14] X. Zhang, D.O. Hayward, D.M.P. Mingos, Catal. Lett. 86 (2003) 235-243.

[15] X. Zhang, C.S.-M. Lee, D.M.P. Mingos, D.O. Hayward, Appl. Catal. A 240 (2003) 183197.

[16] X. Zhang, C.S.-M. Lee, D.M.P. Mingos, D.O. Hayward, Appl. Catal. A 248 (2003) 129142.

[17] Yu.P. Tulenin, M.Yu. Sinev, V.V. Savkin, V.N. Korchak, Catal. Today 91-92 (2004) 155159.

[18] X. Zhang, C.S.-M. Lee, D.O. Hayward, D.M.P. Mingos, Catal. Today 105 (2005) 283-294.

[19] Y. Liu, W.P. Fang, W.Z. Weng, H.L. Wan, J. Mol. Catal. A 239 (2005) 193-200.

[20] V.Yu. Bychkov, Yu.P. Tyulenin, V.N. Korchak, E.L. Aptekar, Appl. Catal. A 304 (2006) 21-29.

[21] V.Yu. Bychkov, Yu.P. Tyulenin, M.M. Slinko, V.N. Korchak, Appl. Catal. A 321 (2007) 180-189.

[22] J.-M. Li, F.-Y. Huang, W.-Z. Weng, X.-Q. Pei, C.-R. Luo, H.-Q. Lin, C.-J. Huang, H.-L. Wan, Catal. Today 131 (2008) 179-187.

[23] V.Yu. Bychkov, Yu.P. Tyulenin, M.M. Slinko, D.P. Shashkin, V.N. Korchak, J. Catal. 267 (2009) 181-187.

[24] M. Wang, W. Weng, H. Zheng, X. Yi, C. Huang, H. Wan, J. Nat. Gas Chem. 18 (2009) 300-305.

[25] V.Yu. Bychkov, Yu.P. Tulenin, M.M. Slinko, V.N. Korchak, Catal. Lett. 119 (2007) 339345.

[26] V.Yu. Bychkov, Yu.P. Tulenin, M.M. Slinko, V.N. Korchak, Catal. Lett. 141 (2011) 602607.

[27] A.Yu. Gladky, V.V. Kaichev, V.K. Ermolaev, V.I. Bukhtiyarov, V.N. Parmon, Kinet. Catal. 46 (2005) 251-259.

[28] A.Yu. Gladky, V.K. Ermolaev, V.N. Parmon, Catal. Lett. 77 (2001) 103-106.

[29] G. Ertl, P.R. Norton, J. Rüstig, Phys. Rev. Lett. 49 (1982) 177-180.

[30] N.A. Collins, S. Sundaresan, Y.J. Chabal, Surf. Sci. 180 (1987) 136-152.

[31] B.C. Sales, J.E. Turner, M.B. Maple, Surf. Sci. 114 (1982) 381-394.

[32] G.I.N. Waterhouse, G.A. Bowmaker, J.B. Metson, Appl. Catal. A 266 (2004) 257-273. 
[33] R. Imbihl, A. Scheibe, Y.F. Zeng, S. Günther, R. Kraehnert, V.A. Kondratenko, M. Baerns, W.K. Offermans, A.P.J. Jansen, R.A. van Santen, Phys. Chem. Chem. Phys. 9 (2007) 3522-3540.

[34] D. Teschner, J. Borsodi, A. Wootsch, Z. Revay, M. Hävecker, A. Knop-Gericke, S.D. Jackson, R. Schlögl, Science 320 (2008) 86-89.

[35] C. Rameshan, W. Stadlmayr, C. Weilach, S. Penner, H. Lorenz, M. Hävecker, R. Blume, T. Rocha, D. Teschner, A. Knop-Gericke, R. Schlögl, N. Memmel, D. Zemlyanov, G. Rupprechter, B. Klötzer, Angew. Chem. Int. Ed. 49 (2010) 3224-3227.

[36] V.I. Bukhtiyarov, V.V. Kaichev, I.P. Prosvirin, Top. Catal. 32 (2005) 3-15.

[37] A. Knop-Gericke, E. Kleimenov, M. Hävecker, R. Blume, D. Teschner, S. Zafeiratos, R. Schlögl, V.I. Bukhtiyarov, V.V. Kaichev, I.P. Prosvirin, A.I. Nizovskii, H. Bluhm, A. Barinov, P. Dudin, M. Kiskinova, Adv. Catal. 52 (2009) 213-272.

[38] S. Doniach, M. Sanjic, J. Phys. C 3 (1970) 285-291.

[39] M. Hävecker, N. Pinna, K. Weiß, H. Sack-Kongehl, R.E. Jentoft, D. Wang, M. Swoboda, U. Wild, M. Niederberger, J. Urban, D.S. Su, R. Schlögl, J. Catal. 236 (2005) 221-232.

[40] D. Alders, F.C. Voogt, T. Hibma, G.A. Sawatzky, Phys. Rev. B 54 (1996) 7716-7719.

[41] N.S. McIntyre, M.G. Cook, Anal. Chem. 47 (1975) 2208-2213.

[42] C.P. Li, A. Proctor, D. Hercules, Appl. Spectrosc. 38 (1984) 880-886.

[43] A.F. Carley, S.D. Jackson, J.N. O’Shea, M.W. Roberts, Surf. Sci. 440 (1999) L868-L874.

[44] S.-J. Oh, J.W. Allen, I. Lindau, J.C. Mikkelsen, Jr., Phys. Rev. B 26 (1982) 4845-4856.

[45] G.A. Rizzi, M. Petukhov, M. Sambi, G. Granozzi, Surf. Sci. 522 (2003) 1-7.

[46] J.C. de Jesus, J. Carrazza, P. Pereira, F. Zaera, Surf. Sci. 397 (1998) 34-47.

[47] G.T. Tyuliev, K.L. Kostov, Phys. Rev. B 60 (1999) 2900-2907.

[48] http://www.quases.com/

[49] S. Tanuma, C.J. Powell, D.R. Penn, Surf. Interf. Anal. 21 (1993) 165-176.

[50] I. Aartun, T. Gjervan, H. Venvik, O. Görke, P. Pfeifer, M. Fathi, A. Holmen, K. Schubert, Chem. Eng. J. 101 (2004) 93-99.

[51] P. Mars, D.W. van Krevelen, Chem. Eng. Sci. 3 (1954) 41-59.

[52] B.L.M. Hendriksen, S.C. Bobaru, J.W.M. Frenken, Catal. Today 105 (2005) 234-243.

[53] B.L.M. Hendriksen, M.D. Ackermann, R. van Rijn, D. Stoltz, I. Popa, O. Balmes, A. Resta, D. Wermeille, R. Felici, S. Ferrer and J.W.M. Frenken, Nature Chem. 2 (2010) 730734. 
[54] M.R. Bassett, R. Imbihl, J. Chem. Phys. 93 (1990) 811-821.

[55] D. Rosenthal, F. Girgsdies, O. Timpe, R. Blume, G. Weinberg, D. Teschner, R. Schlögl, Z. Phys. Chem. 223 (2009) 183-207. 